\title{
Residue on Ignition
}

National Cancer Institute

\section{Source}

National Cancer Institute. Residue on Ignition. NCI Thesaurus. Code C134276.

The amount of residual substance not volatilized after a sample is ig nited. 